Comegando na casa assinaladn com * e teminando na cusa assinalada com **, percorrendo o tabulcirv a salto de cavalo, encontrar-se-äo os nomes de algurs dos laureudos com o Prémio Nobel da Quimica.

\begin{tabular}{|l|l|l|l|l|l|l|l|}
\hline UL & SE & EK & NG & S & OK & RL & KA \\
\hline FO & DI & PA & AB & TH & D & IU & G \\
\hline ST & IN & RD & OS & I & DD & RR & RH \\
\hline GR & RD & AU & TO & NA & EN & AL & NO \\
\hline G & R & IG & DE & TW & V & AR & ER \\
\hline BU & R & DE & HE & ST & R & ML & TT \\
\hline AL & NE & CH & ZI & BY & A & FI & LE \\
\hline NE & R & E & RN & SC & EG & NA & SE \\
\hline
\end{tabular}

\title{
ACTIVIDADES DA S.P.Q.
}

"Case Studies" no Ensino de Química

Realizou-se no Departamento de Química da Faculdade de Ciências do Porto, no passado dia 16 de Maio, o"18 Seminārio da S.P.Q.", intitulado "Case Studies" no Ensino da Química. O programa incluiu uma conferência pelo Prof. Fernando Serrão, se guida de discussão, planeamento de actividades futuras da S.P.Q. e visita à Exposição de Material Científico e Didāctico e a Laboratórios do Departamento.

- Grupo Coordenador do Ensino da Química (S.P.Q.) - delegação de Lisboa. Integram este grupo de trabalho 01inda Bonifácio Osório, Maria da Conceição Alneida e Manuel Mendes da Costa. 
DELEGAÇOEES REGIONAIS

Realizaram-se durante os primeiros meses do corrente ano as eleiçōes para os Corpos Directivos das três Delegações Regionais da Sociedade Portuguesa de Química. us eleitos para o Triénio $1978 / 81$ foram os seguintes:

DELEGAÇÃO DO NORTE: (Sede no Porto)

Assemblcia Regional

Presidente - joão Luís Cabreira de Oliveira Cabral

19 Secretārio - José Luís C. Conceição Figueiredo

2 ? Secretário - Rui Adelino Torcato Barroca

Direç̧ão da Delegação Regional

Presidente - Manuel Aníbal v. Ribeiro da Silva

Secretário - José Alberto Nunes Ferreira Gomes

Vogal - José Luis Fontes da Costa Lima

DELEGAÇÃO DO CENTRO (Sede em Coimbra)

Assembleia Regiona1

Presidente - António J. Campos Varandas

19 Secretário - Júlio António Marques da Cunha Pinto

29 Secretário- Maria Helena Ferreira Teixeira

Direção da Delegação Regional

Presidente - António José Ferrer Correia

Secretário - Maria da Conceição Pedroso Lima

Vogal - Maria Isabel Almeida Ferra

DELEGAÇÃO DO SUL (Sede em Lisboa)

Assembleia Regional

Presidente - José Luís Cardoso Pereira

18 Secretário - José Dias Lopes da Silva

28 Secretário - Carlos José Rodrigues Crispim Romão

Direcção da Delegação Regional

Presidente - Maria Alzira Almoster Ferreira

Secretário - José Miguel da Costa Reis

Vogal - Maria Isabel da Silva Martinho Simões 
Em reunião do Conselho Directivo da SPQ do dia 17 de Maio de 1978 foram eleitos:

\author{
Presidente da Sociedade: Maria Alzira Almoster \\ Ferreira \\ Prof. Cat. da Faculdade de \\ Ciências de Lisboa.
}

\author{
Vice-Presidente da Sociedade: Manuel Aníbal Varejão \\ Ribeiro da Silva \\ Prof. Auxiliar da Faculdade \\ de. Ciências da Universidade \\ d. Porto.
}

FEDERAÇत̃o EUROPEIA DAS SOCIEDADES DE QUIMMICA

GRUPO DE TRABALHO SOBRE O ENSINO DA QUÍMICA

FINALIDADES: A finalidade do Grupo de Trabalho $\bar{e}$ auxiliar as So ciedades nembros (e membros individuais dessas Socie dades) em qualquer actividade destinada a melhorar o ensino e a aprendizagem da Química a todos os níveis. Mais especificamente procura-se:

i) identificar indivíduos e organizações activas em edu cação en química na Europa

ii) facilitar a troca de informação sobre tais indiví duos e organizaçóes e sobre a actividade corrente em educação en química

iii) fornecer oportunidades para a cooperação entre indivíduos e organizações 
iv) contribuir para o desenvolvimento da educação em química organizando conferências, conduzindo estudos e inventários e por outros quaisquer meios.

Realizou-se em Paris, aa sede da Société Chinique de France, em 11 e 12 Abril, a $11^{\mathrm{a}}$. reunião do Grupo de Trabalho sobre - Ensino da Química da Federação Europeia das Sociedades de Quími ca. A SPQ, цue ainda não é membro da Federação, fez-se representar por um observador.

0 Grupo de Trabalho tem, neste momento, 16 membros, representando 13 países europeus. O Presidente é Malcom J.Frazer , Professor de Ensino da Química na Universidade de East Anglia e representante da Chemical Society e do Royal Institute of Chenistry; a secretária é a $\mathrm{Dr}^{\mathrm{a}}$. Ursula Hofacker representante da Gerellschaft Deutscher Chemiker da República Federal Alemã.

Estiveram presentes nesta reunião os representantes da Bélgica, França, RFA, Irlanda, Itālia, Holanda, Folónia, Grã-Bretanha e Yugoslávia além de representantes da IUPAC e da UNESCO.

Os pontos principais da reunião foram:

1) apresentação de relatórios da actividade do Grupo de Trabalho e das Sociedades membros;

2) reunião conjunta com o Grupo de Trabalho sobre Actividades Profissionais, para divisão de tarefas e colaboração;

3) discussão das actividades futuras.

No ponto 3) o delegado português solicitou o apoio deste Grupo de Trabalho para un Encontro sobre o Ensino da Química, a realizar em Lisboa em Outubro ou Novembro do corrente ano (VER NOTÍCIA NA PÁGINA 56). A adesão do Grupo de Trabalho a este pro jecto foi unânime tendo sido constituída para o efeito uma Comis são Organizadora Internacional formada por

A. Romão Dias (Portugal), M.J. Frazer (Grä-Bretanha), P. J. Slootmaekers (Bēlgica) e H. Latreille (França).

Foi ainda proposto que a prōxima reunião do Grupo de Trabalho se realize em Lisboa, na altura do Encontro; sobre este ponto não foi tomada uma decisão final. 
OKGANIZADO POR: SOCIFDADE PORTUGUESA DE QUTMMTCA

EM COIABORAÇ̃̃o COM: GRUPO DE TKABALHO SOBRE FDUCAÇÃO EM QUÍMICA da

FEDFRAÇÃO EUROPEIA DAS SOCIEDADES DE QUÍMICA

LOCAL: LISBOA

DATA PROVÁVEL: OUTUBRO/NOVEMBRO 1978

Fm resposta ao desejo manifestado pela grande maioria dos participantes no 19 Encontro Nacional de Química, encontra- 6 e a SPQ a organizar um Encontro dedicado exclusivamente a problemas da Educação em Química. Procurando ultrapassar o grau de amadorismo geralmente verificado nas discussóes sobre este assunto, a SPQ está a tentar trazer a este Encontro alguns especialistas es trangeiros. Weste sentido jā se conseguiu a colaboração efectiva do Grupo de Trabalho sobre Ensino da Química da Federação Euro reia das Sociedades de Química (ver notícia na pág. ) e o apoio de princípio da IUPAC e da UNESCO estando em curso diligências para concretizar estes dois últimos.

A estrutura proposta para o Encontro é a seguinte:

1) Cerca de 8 conferências, cada uma delas seguida de discussão, espalhando-se por 2 dias, e que estarão abertas a todos os interessados que se inscrevam para tal, sendo a única limitação a da capacidade das instalaçũes.

2) Grupos de Trabalho (entre 5 a 10), cada um com a participação de 10-20 pessoas sob a orientação de um especialista para durante dois dias discutir um tema particular. Os Grupos de Trabalho destinam- se a pessoascom particular interesse em aprofun dar problemas de Educação em Química c/ou que jä tenhan iniciado estudos neste donínio. Estes Grupos de Trabalho devem considerar-se como ponto de partida para estudos que devem ter continuidade. 
Alguns dos Temas propostos para as Conferências e os Grupos de Trabalho são os seguintes:

1. Política actual do ensino da Química em Portugal
a) objectivos do ensino da Química no secundário
b) objectivos do ensino da Química no terciärio
c) política de definição de programas
d) formaçũo de professores para o ensino da Química no secundārio.

2. Investigação em Ensino de Química. Definição, situação actual, tendências.

3. Fstabelecimento de programas. Metas e objectivos.

4. Ensino integrado: Química e Biologia.

5. Ensino integrado: Química e Física.

6. Aspectos industriais e ambientais no ensino da Quimica.

7. Avaliaçio de conhecimentos.

8. Inovação "t nsino da Química.

9. Trabatho de i horatório.

o nümero de inscriçöes para as Conferências e para os Grupos de Trabalho será 1 imitado embora ainda nesta fase de organização não seja ainda possível estabelecer quais os limites.

Para os participantes no Encontro que năo venham a ser integrados nos Grupos de Trabalho será organizado um programa alternativo constando de:
i) exibição de filmes didācticos sobre química
ii) exibiçio de cartazes sobre problemas pontuais do ensino da química
iii) visitas a laboratórios de investigaçăo e a fäbricas.
Neste momento todos os sócios da SPQ devem jä ter re- cebido um impresso para inscriçäo provisória no Encontro. 


\section{ENCONTRO NACIONAL DE QUÍMICA}

Nos dias 3, 4 e 5 de Janeiro de 1979, realizar-se-ä no Porto o 29 Encontro Naciona1 de Química.

\section{A Comissão Organizadora é constituída por:}

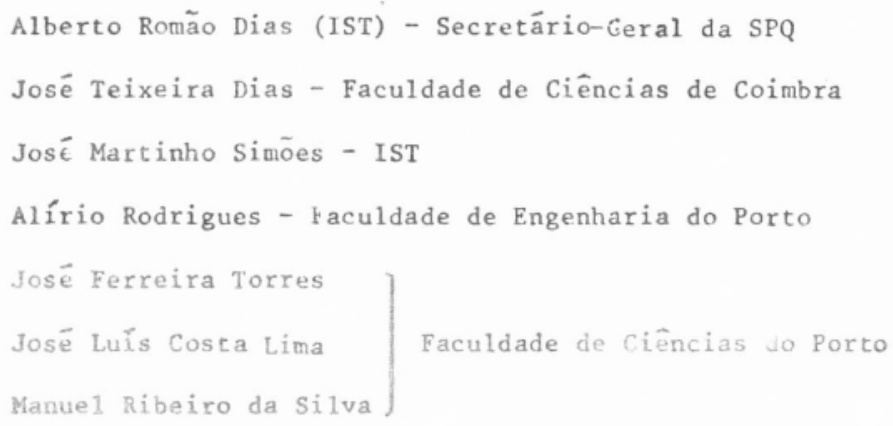

A primeira circular serä distribuída brevemente.

Todas as informaçues relativas a este Encontro devem ser pedidas directamente à

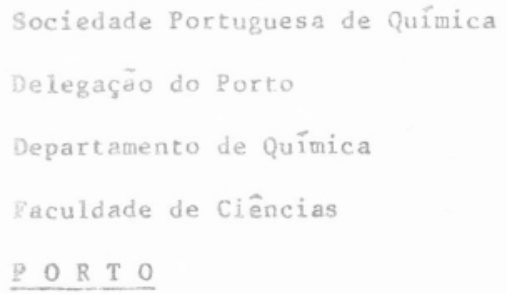




\section{NOTICIARIO NACIONAL}

Palestras de Química - O Departamento de Química da Faculdade de Ciências do Porto e o Centro de Investigação em Química anunciam a lista de temas para Junho das palestras que terão lugar às 5 s. feiras, pelas 16 h no Anfiteatro de Química da Faculdade de Ciências :

Jun. 01 - Tema de Voltametria.

J. Grimshaw (Belfast, N. Ireland) 